\title{
Thermodynamic Analysis of Efficiency- NTU Parameters for Parallel Flow Type Heat Exchanger under the Effect of External Heat Leak
}

\author{
Roopesh Tiwari ${ }^{1}$ and Govind Maheshwari ${ }^{2}$ \\ ${ }^{1}$ Department of Mechanical Engineering, SAGE University, Indore, India \\ ${ }^{2}$ Department of Mechanical Engineering, Institute of Engineering \& Technology, DAVV, Indore, India \\ E-Mail: roopeshyati@gmail.com
}

\begin{abstract}
The work presented here analyses theoretically a parallel flow type heat exchanger which is subjected to external heat leak, from the cold fluid side or from the hot fluid side. Efficiency-NTU relations are developed and the results obtained are presented graphically, reflecting the effect of heat capacity ratios and the heat leak on the efficiency of the heat exchanger. The graphs follow the similar pattern with increasing heat capacity ratios. Also, as the heat leak is increased, the graphs show opposite behavior when the minimum heat capacity is on the hot side to that when the minimum capacity is on the cold side. The derived expressions are reduced to the classical effectiveness-efficiency-NTU relations for the parallel flow type heat exchangers as the heat leak approaches zero.

Keywords: Heat exchanger, Effectiveness, Efficiency, Heat leak, Heat capacity ratio
\end{abstract}

\section{INTRODUCTION}

Heat exchangers are widely used in thermal systems. Owing to the depleting natural resources, the performance appraisal of a heat exchanger has always been a matter of research. Based on arithmetic mean temperature difference (AMTD), optimum heat transfer rate, $\mathrm{Q}_{\mathrm{opt}}$, has been expressed as the product of overall heat transfer coefficient $(\mathrm{U})$, area of the heat exchanger (A) and AMTD, leading to the introduction of heat exchanger efficiency as the ratio of the actual heat transfer rate to optimum heat transfer rate [1,2]. Efficiency analysis has been further done for shell and tube heat exchangers, when the Number of Transfer Units (NTU) and the capacity ratio are known [3], also the work has been done for cross flow heat exchangers [4]. Minimization of entropy has been considered in heat exchanger analysis. The application of this method to heat exchanger was first proposed by McClintock [5]. Bejan [6] introduced a nondimensional parameter, the number of entropy generation units $\mathrm{N}_{\mathrm{s}}$, as a measure of heat exchanger irreversibility. Aceves-saborio et al., [7] extended the irreversibility minimization method by including a term to account for the energy of the heat exchanger material.

Shah and Skiepko showed that the heat exchanger effectiveness can be maximum or minimum at the minimum irreversibility operating point, concluding that effectiveness is not a measure of heat exchanger irreversibility [8]. All the above analysis for effectiveness, efficiency and irreversibility has been done without taking into account the heat exchange between the heat exchanger and the environment. When working at low temperatures, like in cryogenics, the temperature difference between the fluid streams and the surrounding is significant, causing some heat transfer between the heat exchanger and the surroundings, leading to poor performance of the heat exchanger. Work has been carried out on finite time thermodynamic considering the heat resistance losses in the hot and cold side heat exchangers [9]. Chowdhury and Sarangi [10] analyzed counter flow heat exchanger by considering the cold side having the minimum capacity and subjected to heat leak. Barron [11] presented the work when there is heat leak either in the hot side or the cold side of the counter flow heat exchanger. Effectiveness-NTU relations have been derived for parallel flow heat exchangers with heat leakage [12].

The work presented here aims to solve analytically the efficiency-NTU relation for a parallel flow type heat exchanger subjected to heat leak from outside. Efficiency of the heat exchanger based on optimum heat transfer has been derived in terms of effectiveness and NTU, simultaneously incorporating the heat leak in the hot fluid and cold fluid side. Further, the mathematical model is developed by considering hot fluid side having the minimum heat capacity and cold fluid side having the minimum heat capacity respectively. To give the better idea of the heat exchanger performance, the results are presented graphically by varying the heat capacity ratios. The equations and relationships developed in the present work provide an overview to design a heat exchanger when it meets a significant heat leakage.

\section{ANALYTICAL SOLUTION}

Consider a parallel flow heat exchanger with heat leak from both, the hot fluid side and cold fluid side, as shown in figure 1 and figure 2. 


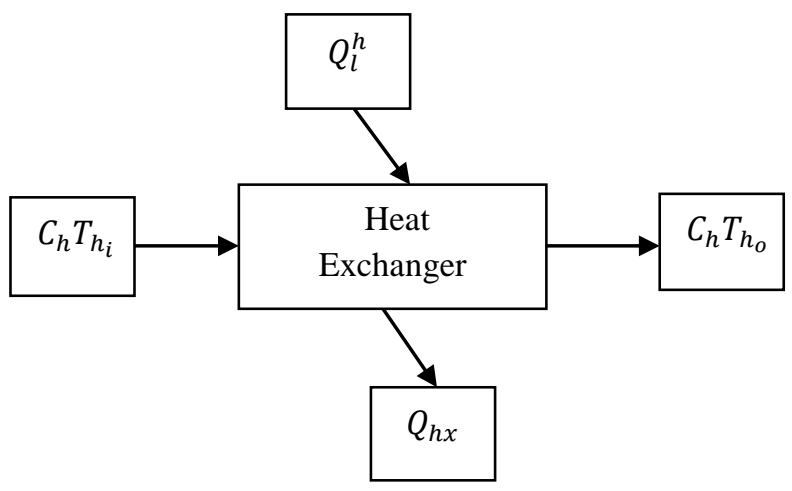

Fig. 1 Heat Transfer in Hot Side of the Parallel Flow Heat Exchanger

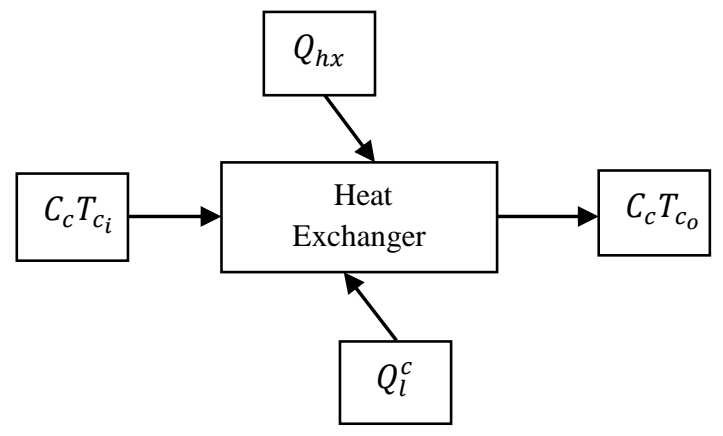

Fig.2 Heat Transfer in Cold Side of the Parallel Flow Heat Exchanger

In the above figures, $Q_{l}^{h}$ and $Q_{l}^{c}$ are the heat leaks in the hot fluid side and cold fluid side respectively. $C_{h}$ and $C_{c}$ are the heat capacities of hot fluid and cold fluid, $T_{h_{i}}$ and $T_{h_{o}}$ are the inlet and outlet temperatures of hot fluid, $T_{c_{i}}$ and $T_{c_{0}}$ are the inlet and outlet temperatures of the cold fluid. $Q_{h x}$ is the heat transferred to the cold fluid by the hot fluid.

The energy balance on both the hot and cold fluid gives, respectively as,

$$
\begin{aligned}
C_{h}\left(T_{h_{i}}-T_{h_{o}}\right)+Q_{l}^{h} & =Q_{h x} \\
C_{c}\left(T_{c_{0}}-T_{c_{i}}\right)-Q_{l}^{c} & =Q_{h x}
\end{aligned}
$$

Heat exchanger efficiency $(\eta)$ is defined as the ratio of the actual rate of heat transfer in the heat exchanger $\left(Q_{a c t}\right)$ to the optimum rate of heat transfer $\left(\mathrm{Q}_{\text {opt }}\right)[2]$,

$\eta=\frac{Q_{a c t}}{Q_{o p t}}$

Using Eq (1) and Eq (2),the efficiency on the hot side $\left(\eta^{h}\right)$ and the efficiency on the cold side $\left(\eta^{c}\right)$ can be written as,

$\eta^{h}=\frac{Q_{h x}}{Q_{o p t}}=\frac{C_{h}\left(T_{h_{i}}-T_{h_{o}}\right)+Q_{l}^{h}}{U A\left(\frac{\left(T_{h_{i}}+T_{h_{o}}\right)}{2}-\frac{\left(T_{c_{i}+T_{c_{0}}}\right)}{2}\right)}$ and

$\eta^{c}=\frac{Q_{h x}}{Q_{o p t}}=\frac{C_{c}\left(T_{c_{0}}-T_{c_{i}}\right)-Q_{l}^{c}}{U A\left(\frac{\left(T_{h_{i}}+T_{h_{o}}\right)}{2}-\frac{\left(T_{\left.c_{i}+T_{c_{0}}\right)}\right)}{2}\right)}$
Where $Q_{o p t}$ is optimum heat transfer rate and can be written as:

$Q_{\text {opt }}=U \cdot A \cdot A M T D$

Using $\mathrm{Eq}(1)$ and $\mathrm{Eq}(2)$, one can get,

$T_{h_{o}}-T_{h_{i}}=-\frac{Q_{h x}}{C_{h}}+\frac{Q_{l}^{h}}{C_{h}}$ and $T_{c_{i}}-T_{c_{0}}=-\frac{Q_{h x}}{C_{c}}-\frac{Q_{l}^{c}}{C_{c}}$

On simplification, Eq (6) can be written as

$T_{h_{o}}-T_{c_{0}}=-\frac{Q_{h x}}{C_{h}}+\frac{Q_{l}^{h}}{C_{h}}-\frac{Q_{h x}}{C_{c}}-\frac{Q_{l}^{c}}{C_{c}}+\left(T_{h_{i}}-T_{c_{i}}\right)$

Substituting Eq (7) in Eq (4), one can get efficiency on hot side $\left(\eta^{h}\right)$ as,

$\eta^{h}=\frac{C_{h}\left(T_{h_{i}}-T_{h_{o}}\right)+Q_{l}^{h}}{\frac{U A}{2}\left(\frac{Q_{l}^{h}}{C_{h}}-\frac{Q_{l}^{c}}{C_{c}}-\frac{Q_{h x}}{C_{h}}-\frac{Q_{h x}}{C_{c}}+2\left(T_{h_{i}}-T_{c_{i}}\right)\right)}$

Combining Eq (1) and Eq (8), the efficiency $\left(\eta^{h}\right)$ is obtained as,

$\eta^{h}=\frac{C_{h}\left(T_{h_{i}}-T_{h_{o}}\right)+Q_{l}^{h}}{\frac{U A}{2}\left(\frac{Q_{l}^{h}}{\left.C_{h}-\frac{Q_{l}^{c}}{C_{c}}-\frac{C_{h}\left(T_{h_{i}}-T_{h_{o}}\right)+Q_{l}^{h}}{C_{h}}-\frac{C_{h}\left(T_{h_{i}}-T_{h_{o}}\right)+Q_{l}^{h}}{C_{h}}+2\left(T_{h_{i}}-T_{c_{i}}\right)\right)}\right.}$

Considering hot fluid having the minimum heat capacity, i.e., $C_{h}=C_{\min }$, the actual effectiveness when the hot fluid is having minimum heat capacity $\left(\varepsilon_{a c t}^{h}\right)$, will become

$\varepsilon_{a c t}^{h}=\frac{T_{h_{i}}-T_{h_{o}}}{T_{h_{i}}-T_{c_{i}}}$ 
Using Eq (9) and Eq (10), one can get the efficiency $\left(\eta^{h}\right)$ as

$$
\begin{aligned}
& c_{h}\left(T_{h_{i}}-T_{h_{o}}\right) / c_{h}\left(T_{h_{i}}-T_{c_{i}}\right)^{+}{ }^{Q_{l}^{h}} / Q_{\max }^{h} \\
& =\frac{}{\frac{U A}{2}\left(\begin{array}{c}
-\frac{Q_{l}^{c}}{C_{C} \cdot C_{h}\left(T_{h_{i}}-T_{c_{i}}\right)} \frac{\left(T_{h_{i}}-T_{h_{o}}\right)}{C_{h}\left(T_{h_{i}}-T_{c_{i}}\right)}-\frac{C_{h}\left(T_{h_{i}}-T_{h_{o}}\right)}{C_{c} \cdot C_{h}\left(T_{h_{i}}-T_{c_{i}}\right)} \\
-\frac{Q_{l}^{h}}{C_{c} \cdot C_{h}\left(T_{h_{i}}-T_{c_{i}}\right)}+\frac{2\left(T_{h_{i}}-T_{c_{i}}\right)}{C_{h}\left(T_{h_{i}}-T_{c_{i}}\right)}
\end{array}\right)}
\end{aligned}
$$

where Maximum heat transfer rate $Q_{\max }^{h}=C_{h}\left(T_{h_{i}}-T_{c_{i}}\right)$ On simplifying Eq (11), one can obtain

$$
\begin{aligned}
& \varepsilon_{a c t}^{h}+Q_{l}^{h} / Q_{\max }^{h} \\
& \eta^{h}=\frac{\left.\frac{Q_{l}^{c}}{2} \cdot N T U_{h} \cdot R_{h}-\varepsilon_{a c t^{\prime}}^{h} \cdot N T U_{h}-\varepsilon_{a c t}^{h} \cdot N T U_{h} \cdot R_{h}-\frac{Q_{l}^{h}}{Q_{\max }^{h}} \cdot N T U_{h} \cdot R_{h}\right)}{+2 \cdot N T U_{h}}
\end{aligned}
$$

where $R_{h}$ is the heat capacity ratio when the hot fluid is having minimum heat capacity, $\mathrm{NTU}_{\mathrm{h}}$ is the number of transfer units when the hot fluid is having minimum heat capacity.

Considering cold fluid having the minimum heat capacity, i.e., $C_{c}=C_{\min }$, the actual effectiveness when the cold fluid is having minimum heat capacity $\left(\varepsilon_{a c t}^{c}\right)$, will become

$\varepsilon_{\text {act }}^{c}=\frac{T_{c_{o}}-T_{c_{i}}}{T_{h_{i}}-T_{c_{i}}}$
Using Eq (12) and Eq (13), one can get the efficiency on the cold side $\left(\eta^{c}\right)$ as

$$
\begin{aligned}
& \eta^{c}= \\
& c_{c}\left(T_{c_{o}}-T_{c_{i}}\right) / c_{c}\left(T_{h_{i}}-T_{c_{i}}\right)^{-} Q_{l}^{c} / Q_{\max }^{c} \\
& \overline{\frac{U A}{2}\left(\begin{array}{c}
\frac{Q_{l}^{h}}{C_{h} \cdot C_{c}\left(T_{h_{i}}-T_{c_{i}}\right)} \frac{C_{c}\left(T_{c_{O}}-T_{c_{i}}\right)}{C_{h} \cdot C_{c}\left(T_{h_{i}}-T_{c_{i}}\right)}+\frac{Q_{l}^{c}}{C_{h} \cdot C_{c}\left(T_{h_{i}}-T_{c_{i}}\right)}-\frac{\left(T_{c_{o}}-T_{c_{i}}\right)}{C_{c}\left(T_{h_{i}}-T_{c_{i}}\right)} \\
+\frac{2\left(T_{h_{i}}-T_{c_{i}}\right)}{C_{c}\left(T_{h_{i}}-T_{c_{i}}\right)}
\end{array}\right)}
\end{aligned}
$$

where maximum heat transfer rate on cold side, $Q_{\max }^{c}=C_{c}\left(T_{h_{i}}-T_{c_{i}}\right)$

On simplifying $\mathrm{Eq}(14)$, one can obtain

$\eta^{c}=$
$\frac{\varepsilon_{a c t}^{c}-Q_{l}^{c} / Q_{\text {max }}^{c}}{\frac{1}{2}\left(\frac{Q_{l}^{h}}{Q_{\text {max }}^{c}} \cdot N T U_{c} \cdot R_{c}-\varepsilon_{a c t}^{c} \cdot N T U_{c} \cdot R_{c}+\frac{Q_{l}^{c}}{Q_{\text {max }}^{c}} \cdot N T U_{c} \cdot R_{c}-\varepsilon_{a c t}^{c} \cdot N T U_{c}+2 \cdot N T U_{c}\right)}$

Where $R_{c}$ is the heat capacity ratio when the cold fluid is

\begin{tabular}{|c|c|c|c|c|}
\hline & $\begin{array}{l}\text { Minimum capacity in the } \\
\text { hot side }\left(\mathrm{R}_{\mathrm{h}} \neq 0\right)\end{array}$ & $\begin{array}{l}\text { Minimum capacity in the } \\
\text { cold side }\left(R_{c} \neq 0\right)\end{array}$ & $\begin{array}{l}\text { Minimum capacity } \\
\text { in the hot side } \\
\left(\mathrm{R}_{\mathrm{h}}=0\right. \\
\Rightarrow \text { evaporator })\end{array}$ & $\begin{array}{l}\text { Minimum capacity } \\
\text { in the cold side } \\
\left(\mathrm{R}_{\mathrm{c}}=0\right. \\
\Rightarrow \text { condenser })\end{array}$ \\
\hline $\begin{array}{l}Q_{l}^{c} \\
=0.0\end{array}$ & $\begin{array}{l}\eta^{h} \\
=\frac{\varepsilon_{a c t}^{h}+Q_{l}^{h} / Q_{\max }^{h}}{\frac{1}{2}\left(\begin{array}{l}-\varepsilon_{a c t}^{h} \cdot N T U_{h}-\varepsilon_{a c t}^{h} \cdot N T U_{h} \cdot R_{h} \\
-\frac{Q_{l}^{h}}{Q_{\max }^{h}} \cdot N T U_{h} \cdot R_{h}+2 \cdot N T U_{h}\end{array}\right)}\end{array}$ & $\begin{array}{l}\eta^{c} \\
\left.=\frac{\varepsilon_{a c t}^{c}}{\frac{1}{2}\left(\begin{array}{c}Q_{l}^{h} \\
Q_{\max }^{c} \\
-\varepsilon_{a c t}^{c} \cdot N T U_{c} \cdot R_{c}-\varepsilon_{a c t}^{c} \cdot N T U_{c}+2 \cdot N T U_{c}\end{array}\right)}\right)\end{array}$ & $\begin{array}{l}\eta^{h} \\
=\frac{\varepsilon_{a c t}^{h}+Q_{l}^{h} / Q_{\max }^{h}}{\frac{1}{2}\left(\begin{array}{c}-\varepsilon_{a c t}^{h} \cdot N T U_{h} \\
+2 \cdot N T U_{h}\end{array}\right)}\end{array}$ & $\begin{array}{l}\eta^{c} \\
=\frac{\varepsilon_{a c t}^{c}}{\frac{1}{2}\left(\begin{array}{c}-\varepsilon_{a c t}^{c} \cdot N T U_{c} \\
+2 \cdot N T U_{c}\end{array}\right)}\end{array}$ \\
\hline $\begin{array}{l}Q_{l}^{h} \\
=0.0\end{array}$ & $\begin{array}{l}\eta^{h} \\
=\frac{\varepsilon_{a c t}^{h}}{\frac{1}{2}\left(\begin{array}{c}-\frac{Q_{l}^{c}}{Q_{\max }^{h}} \cdot N T U_{h} \cdot R_{h}-\varepsilon_{a c t}^{h} \cdot N T U \\
-\varepsilon_{a c t}^{h} \cdot N T U_{h} \cdot R_{h}+2 \cdot N T U_{h}\end{array}\right.}\end{array}$ & $\begin{array}{l}\eta^{c} \\
=\frac{\varepsilon_{a c t}^{c}-Q_{l}^{c} / Q_{\max }^{c}}{\frac{1}{2}\left(\begin{array}{c}-\varepsilon_{a c t}^{c} \cdot N T U_{c} \cdot R_{c}+\frac{Q_{l}^{c}}{Q_{\max }^{c}} \cdot N T U_{c} \cdot R \\
-\varepsilon_{a c t}^{c} \cdot N T U_{c}+2 \cdot N T U_{c}\end{array}\right.}\end{array}$ & $\begin{array}{l}\eta^{h} \\
=\frac{\varepsilon_{a c t}^{h}}{\frac{1}{2}\left(\begin{array}{c}-\varepsilon_{a c t}^{h} \cdot N T U_{h} \\
+2 \cdot N T U_{h}\end{array}\right)}\end{array}$ & $\begin{array}{l}\eta^{c} \\
=\frac{\varepsilon_{a c t}^{c}-Q_{l}^{c} / Q_{\max }^{c}}{\frac{1}{2}\left(\begin{array}{c}-\varepsilon_{a c t}^{c} \cdot N T U_{c} \\
+2 \cdot N T U_{c}\end{array}\right)}\end{array}$ \\
\hline $\begin{array}{l}Q_{l}^{h} \\
=Q_{l}^{c} \\
=0.0\end{array}$ & $\begin{array}{l}\eta^{h} \\
=\frac{\varepsilon_{a c t}^{h}}{\frac{1}{2}\left(\begin{array}{c}-\varepsilon_{a c t}^{h} \cdot N T U_{h}-\varepsilon_{a c t}^{h} \cdot N T U_{h} \cdot R_{h} \\
+2 \cdot N T U_{h}\end{array}\right.}\end{array}$ & $\begin{array}{l}\eta^{c} \\
=\frac{\varepsilon_{a c t}^{c}}{\frac{1}{2}\left(\begin{array}{c}-\varepsilon_{a c t}^{c} \cdot N T U_{c} \cdot R_{c}-\varepsilon_{a c t}^{c} \cdot N T U_{c} \\
+2 \cdot N T U_{c}\end{array}\right)}\end{array}$ & $\begin{array}{l}\eta^{h} \\
=\frac{\varepsilon_{a c t}^{h}}{\frac{1}{2}\left(\begin{array}{c}-\varepsilon_{a c t}^{h} \cdot N T U_{h} \\
+2 \cdot N T U_{h}\end{array}\right)}\end{array}$ & $\begin{array}{l}\eta^{c} \\
=\frac{\varepsilon_{a c t}^{c}}{\frac{1}{2}\left(\begin{array}{c}-\varepsilon_{a c t}^{c} \cdot N T U_{c} \\
+2 \cdot N T U_{c}\end{array}\right)}\end{array}$ \\
\hline
\end{tabular}
having minimum heat capacity, $\mathrm{NTU}_{\mathrm{c}}$ is the number of transfer units when the cold fluid is having minimum heat capacity.

Different cases can be derived from Eq (12) and Eq (15) as shown in table I.

TABLE I DIFFERENT CASES DERIVED FROM EQ (12) AND EQ (15) 


\section{RESULTS AND DISCUSSIONS}

The variations of efficiency with NTU have been presented in figures 3 to 14 , for different heat capacity ratios, in the presence of external heat leak. Figures 3 to 6 represent the cases when the heat capacity ratio $(\mathrm{R})$ is 0.25 . When the minimum heat capacity is on the hot $\operatorname{side}\left(C_{h}=C_{\text {min }}\right)$, the efficiency increases with the increase in the heat leak, the heat leak being either on the hot side or on the cold side, as shown in fig. 3 and fig. 6 . On the other hand the efficiency has a decreasing trend with the increase in the heat leak, when the minimum heat capacity is on the cold side, the heat leak being either on the hot side or on the cold side as shown in fig. 4 and fig. 5

This behavior can be explained in the vicinity of energy balance on hot fluid side and cold fluid side, in the presence of heat leak. When the heat leak is in the cold side, the energy balance on the cold side from Eq (2) is given as,

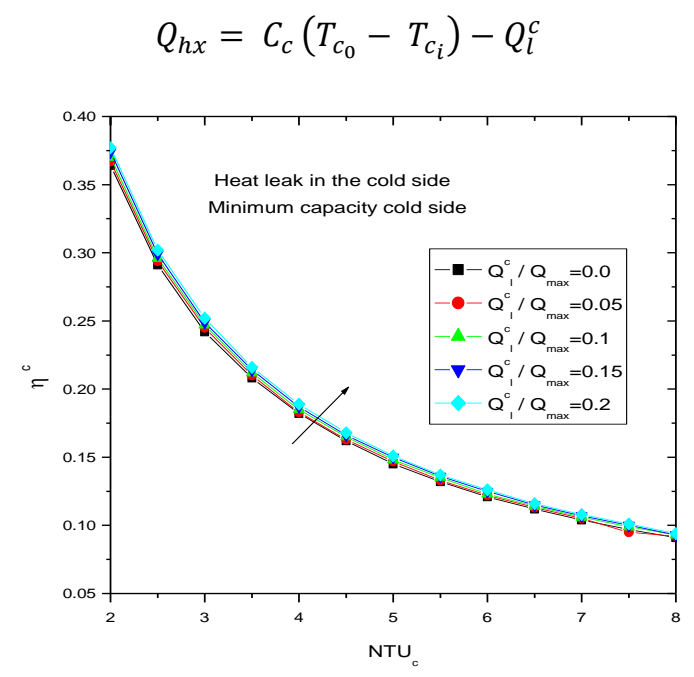

Fig. 3 Efficiency as a function of NTU for various values of dimensionless heat leak $\left(\mathrm{R}_{\mathrm{c}}=0.25, \varepsilon_{\text {act }}^{c}=0.6\right)$

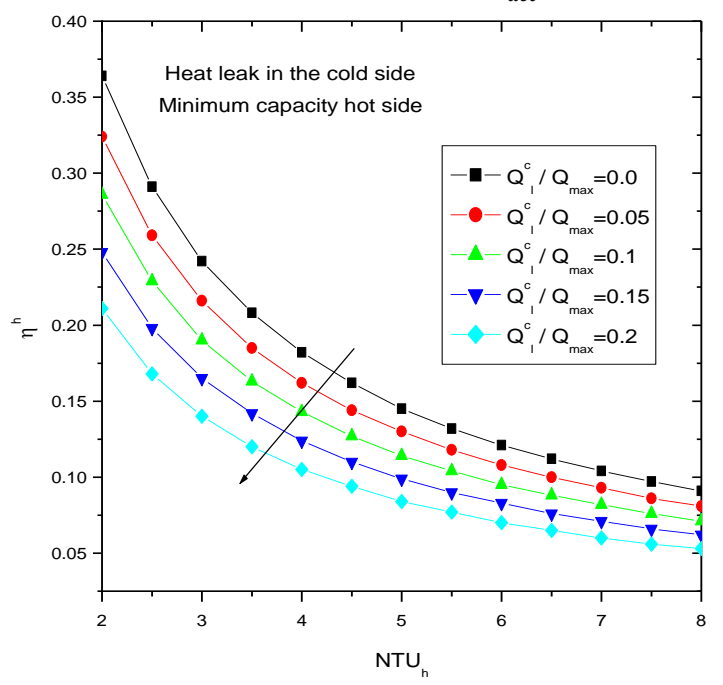

Fig.4 Efficiency as a function of NTU for various values of dimensionless heat leak $\left(\mathrm{R}_{\mathrm{h}}=0.25, \varepsilon_{a c t}^{h}=0.6\right)$

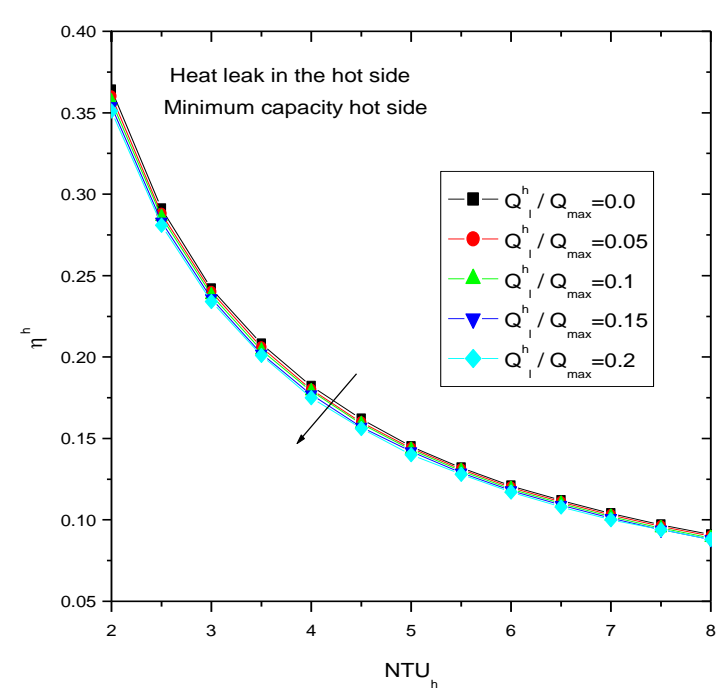

Fig.5 Efficiency as a function of NTU for various values of dimensionless heat leak $\left(\mathrm{R}_{\mathrm{h}}=0.25, \varepsilon_{a c t}^{h}=0.6\right)$

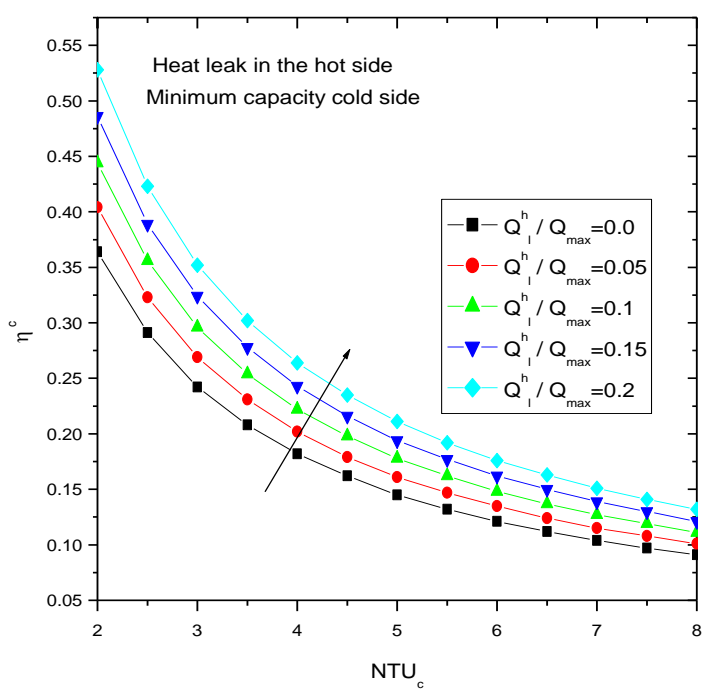

Fig.6 Efficiency as a function of NTU for various values of dimensionless heat leak $\left(\mathrm{R}_{\mathrm{c}}=0.25, \varepsilon_{a c t}^{c}=0.6\right)$

With increase in the heat leak, the difference of outlet temperature of cold fluid and inlet temperature of cold fluid $\left(T_{c_{0}}-T_{c_{i}}\right)$ should increase in order to satisfy the energy balance as depicted in above equation. As the inlet temperature of the cold fluid $\left(T_{c_{i}}\right)$ is constant, outlet temperature of the cold fluid $\left(T_{c_{0}}\right)$ must increase to satisfy the above condition. As $T_{c_{0}}$ increases, the efficiency $\left(\eta^{c}\right)$ will also increase consequently when the minimum capacity is on the cold side. This behavior can also be seen from Eq (4) and same has been exhibited in figure 3 .

Furthermore, the increase in outlet temperature of cold fluid $\left(T_{c_{0}}\right)$ will cause the outlet temperature of the hot fluid $\left(T_{h_{o}}\right)$ to increase thus reducing the difference of the inlet temperature of hot fluid and outlet temperature of hot fluid, $\left(T_{h_{i}}-T_{h_{o}}\right)$. Hence the efficiency $\left(\eta_{h}\right)$ will decrease with increase in the heat leak in the cold side when the minimum capacity is on the hot side. The same has been exhibited in fig. 4. 


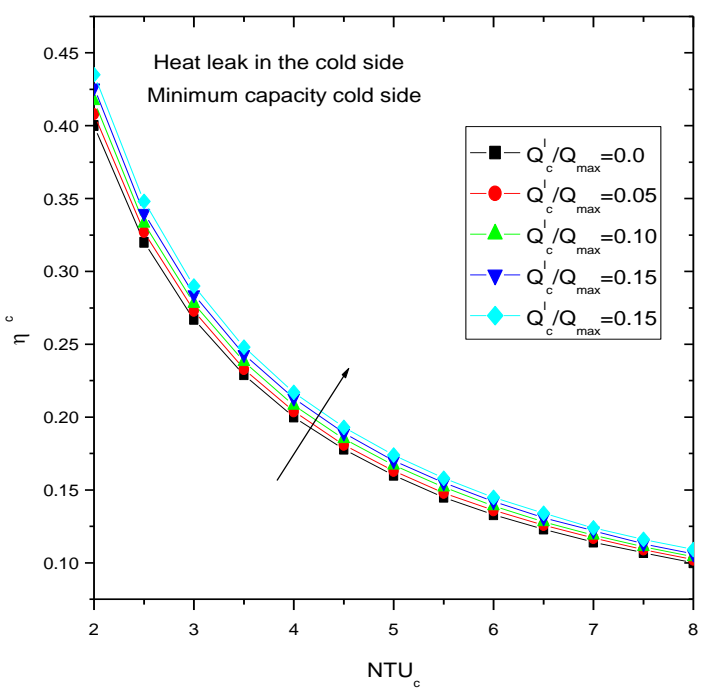

Fig. 7 Efficiency as a function of NTU for various values of dimensionless heat leak $\left(\mathrm{R}_{\mathrm{c}}=0.50, \varepsilon_{a c t}^{c}=0.6\right)$

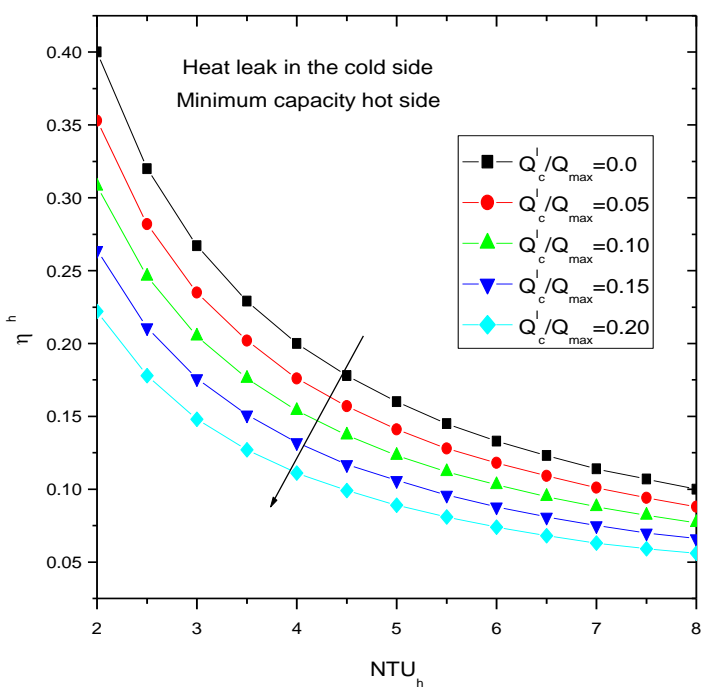

Fig. 8 Efficiency as a function of NTU for various values of dimensionless heat leak $\left(\mathrm{R}_{\mathrm{h}}=0.50, \varepsilon_{\text {act }}^{h}=0.6\right)$

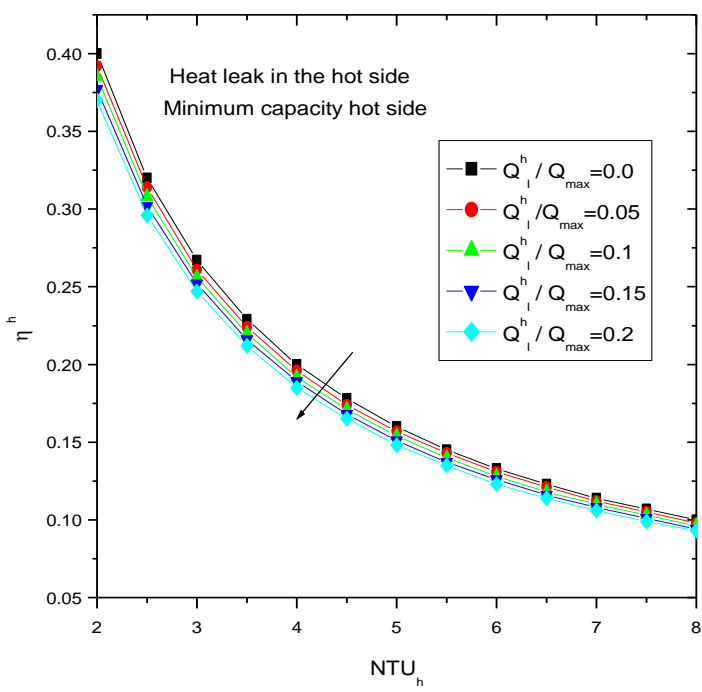

Fig. 9 Efficiency as a function of NTU for various values of dimensionless heat leak $\left(\mathrm{R}_{\mathrm{h}}=0.50, \varepsilon_{a c t}^{h}=0.6\right)$

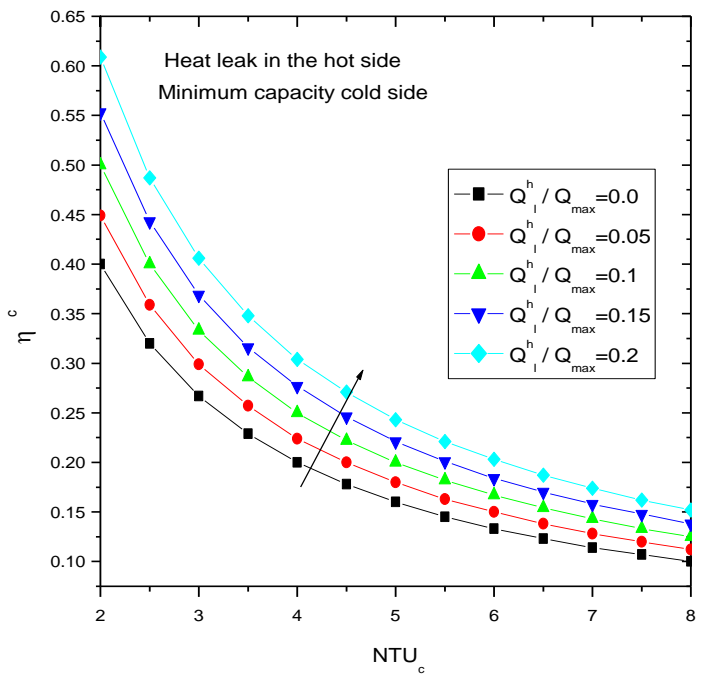

Fig. 10 Efficiency as a function of NTU for various values of dimensionless heat leak $\left(\mathrm{R}_{\mathrm{c}}=0.50, \varepsilon_{a c t}^{c}=0.6\right)$

Similarly, when the heat leak is in the hot side, the energy balance on the hot side from Eq (2) is given as,

$$
C_{h}\left(T_{h_{i}}-T_{h_{o}}\right)+Q_{l}^{h}=Q_{h x}
$$

With increase in the heat leak, the difference of inlet temperature of the hot fluid and outlet temperature of the hot fluid $\left(T_{h_{i}}-T_{h_{o}}\right)$ should decrease in order to satisfy the energy balance as depicted in $\mathrm{Eq}$ (2). As the inlet temperature of the hot fluid $\left(T_{h_{i}}\right)$ is constant, outlet temperature of the hot fluid $\left(T_{h_{0}}\right)$ must increase to satisfy the above condition. As $T_{h_{0}}$ increases, the efficiency $\left(\eta_{h}\right)$ must decrease with the increase in the heat leak, when the minimum capacity is on the hot side as exhibited in figure 5 .

The increase in outlet temperature of the hot fluid $\left(T_{h_{0}}\right)$ will cause the outlet temperature of the cold fluid $\left(T_{c_{o}}\right)$ to increase thus increasing the difference of the outlet temperature of cold fluid and inlet temperature of cold fluid, $\left(T_{c_{0}}-T_{c_{i}}\right)$. Hence the efficiency $\left(\eta_{c}\right)$ will increase with the increase in the heat leak on the hot side, when the minimum capacity is on the cold side, figure 6 . The same reasons are valid for figures 7 to 14 for different heat capacity ratios.

Also, it is observed that, higher the values of NTU, i.e., with increasing size of the heat exchanger, there is a continuous decrease in the efficiency for all the four cases when the heat exchanger is subjected to heat leak. The decline is sharp when the values of NTU are on the lower side and for the higher values of NTU, the decline is gradual.

As the value of $\mathrm{R}$ is increased, the efficiency has an increasing trend for all the four cases discussed for figure 1 . Also, the results have been obtained for heat capacity ratio to be zero, for different values of heat leak parameter, as shown in fig. 15 and fig. 16.. When heat leak and heat capacity ratio are zero, the efficiency equations for both hot and cold fluid sides are reduced to classical effectivenessefficiency-NTU relationship. 


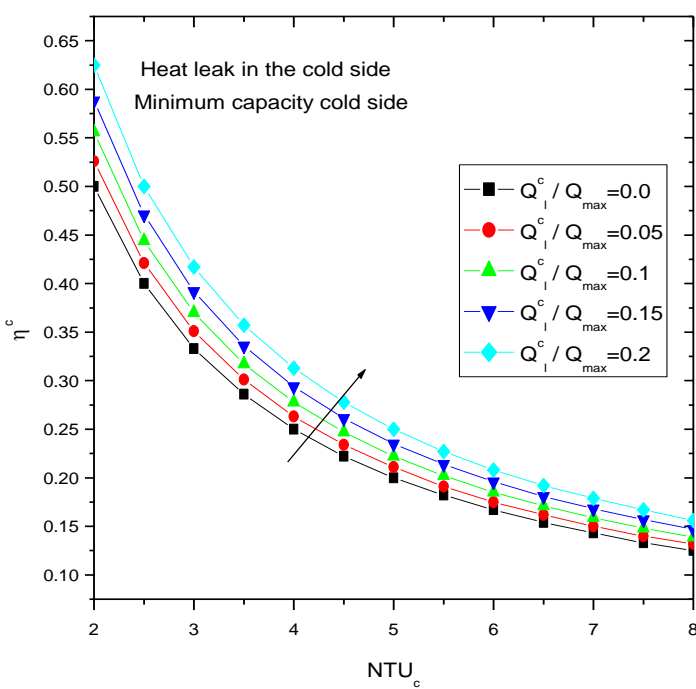

Fig. 11 Efficiency as a function of NTU for various values of dimensionless heat leak $\left(\mathrm{R}_{\mathrm{c}}=1.0, \varepsilon_{a c t}^{c}=0.6\right)$

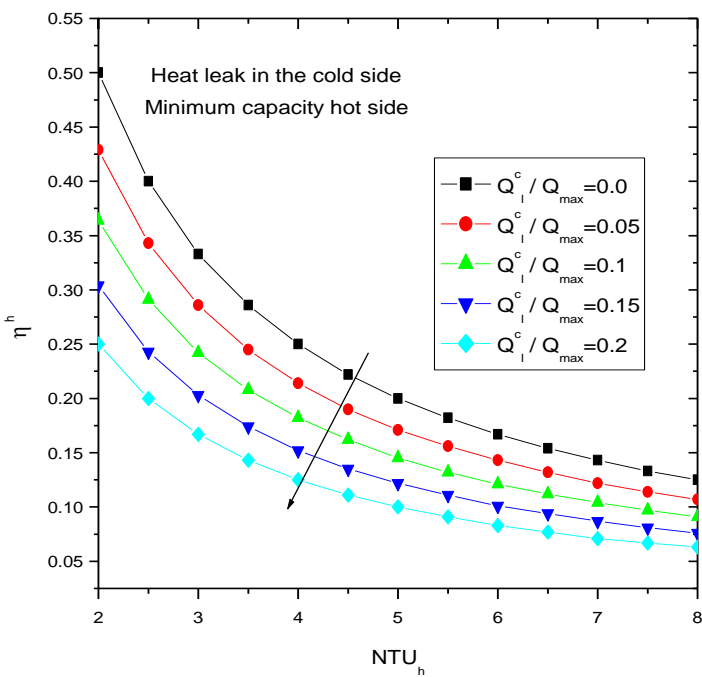

Fig. 12 Efficiency as a function of NTU for various values of dimensionless heat leak $\left(\mathrm{R}_{\mathrm{h}}=1.0, \varepsilon_{a c t}^{h}=0.6\right)$

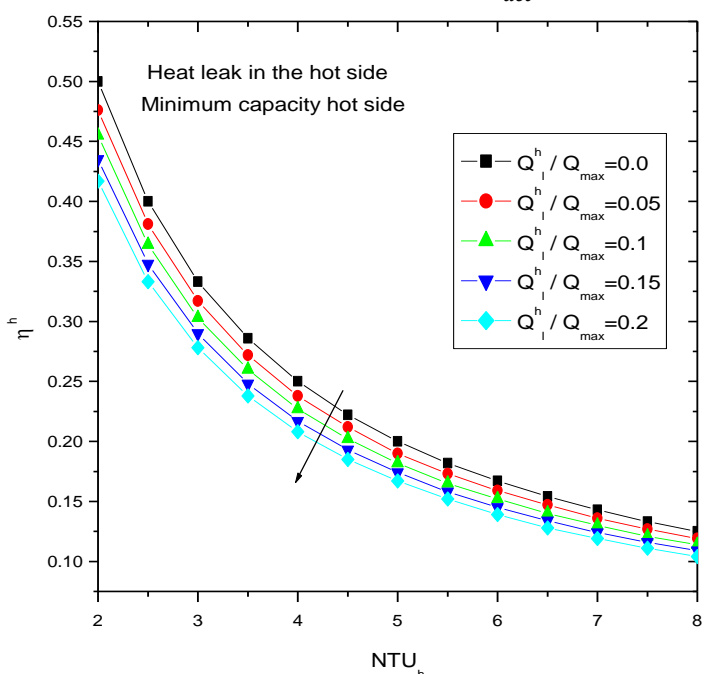

Fig. 13 Efficiency as a function of NTU for various values of dimensionless heat leak $\left(\mathrm{R}_{\mathrm{h}}=1.0, \varepsilon_{a c t}^{h}=0.6\right)$

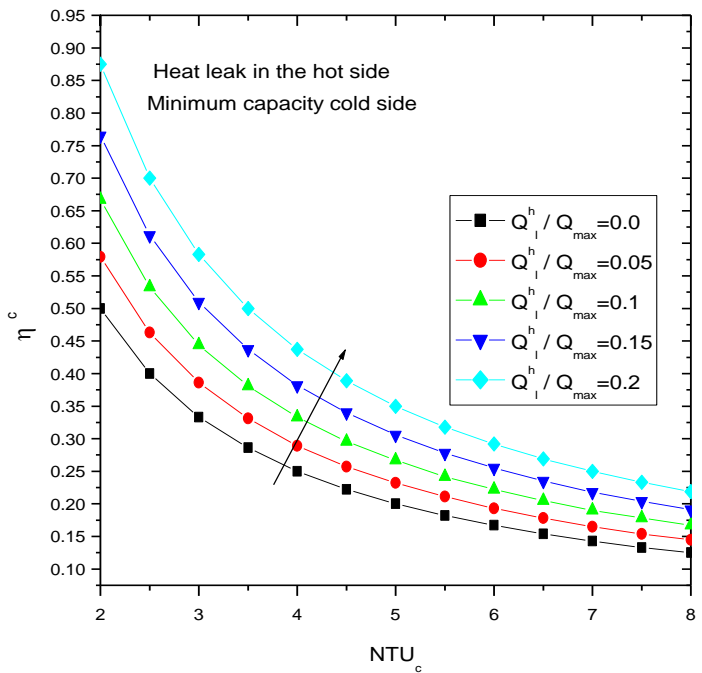

Fig. 14 Efficiency as a function of NTU for various values of dimensionless heat leak $\left(\mathrm{R}_{\mathrm{c}}=1.0, \varepsilon_{\text {act }}^{c}=0.6\right)$

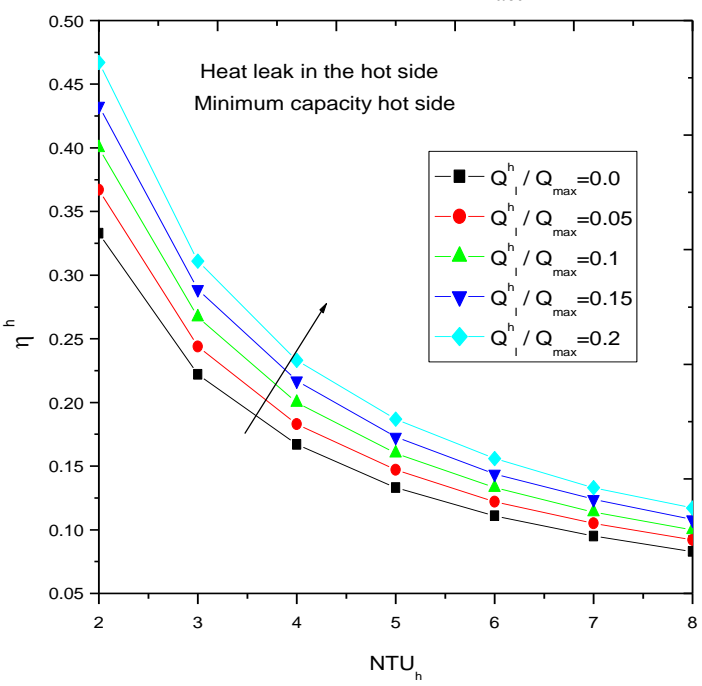

Fig. 15 Efficiency as a function of NTU for various values of dimensionless heat leak $\left(\mathrm{R}_{\mathrm{h}}=0, \varepsilon_{a c t}^{h}=0.6\right)$

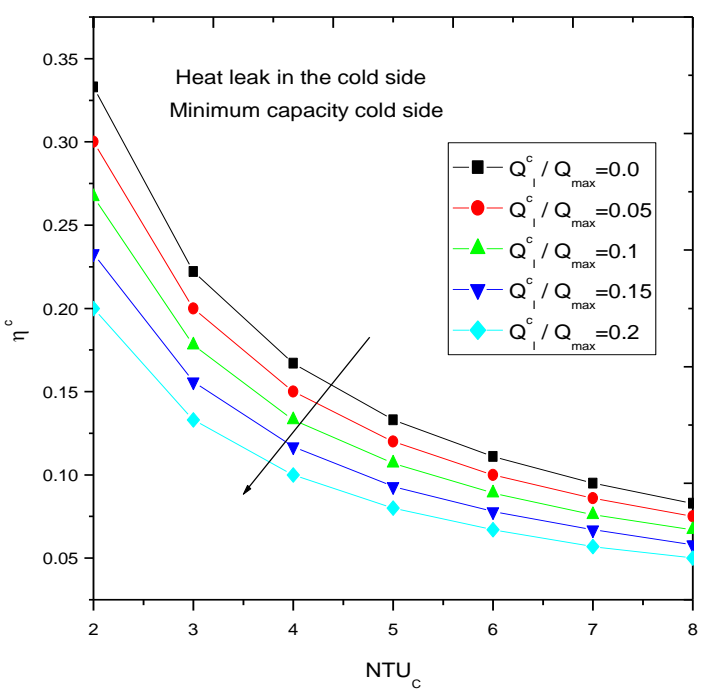

Fig. 16 Efficiency as a function of NTU for various values of dimensionless heat leak $\left(\mathrm{R}_{\mathrm{c}}=0, \varepsilon_{a c t}^{c}=0.6\right)$ 


\section{CONCLUSION}

The analytical solution of the efficiency-NTU relations for the parallel flow heat exchanger, subjected to uniform external heat, has been discussed in the paper. The heat leak is being either in the cold fluid side or in the hot fluid side. The solutions given and the graphs so obtained can be used for wide varieties of application. The analytical solutions so obtained can also be used for non-uniform heat leak. For this the heat exchanger has to be fragmented and the analysis has to be performed on each segment of the heat exchanger.

\section{Appendix: Nomenclature}

A heat transfer surface area, $\mathrm{m}^{2}$

AMTD arithmetic mean temperature difference, ${ }^{\circ} \mathrm{C}$

$C$ heat capacity, $\mathrm{W} / \mathrm{K}$

LMTD log mean temperature difference, ${ }^{\circ} \mathrm{C}$

$N T U$ number of transfer units

$Q \quad$ heat transfer rate, $\mathrm{W}$

$R \quad$ heat capacity ratio

$T \quad$ temperature, ${ }^{\circ} \mathrm{C}$

$U \quad$ overall heat transfer coefficient, $\mathrm{W} / \mathrm{m}^{2} \cdot \mathrm{K}$

\section{Greek Symbols}

$\varepsilon \quad$ effectiveness

$\eta \quad$ efficiency

\section{Subscripts}

act actual

c cold side

$h \quad$ hot side

$h x \quad$ pertaining to heat exchange between hot fluid and cold fluid

$i \quad$ inlet

$l \quad$ pertaining to heat leak

max maximum

min minimum

$o \quad$ outlet

\section{Superscripts \\ c $\quad$ cold side \\ $h \quad$ hot side}

\section{REFERENCES}

[1] A. Fakheri, "Arithmetic Mean Temperature Difference and the Concept of Heat Exchanger Efficiency", Proceedings of the 2003 ASME Summer Heat Transfer Conference, July 21-23, 2003, Paper No. HT2003-47360

[2] A. Fakheri, "Heat Exchanger efficiency", ASME, Vol. 129, pp. 12681276, 2007.

[3] A. Fakheri, "The Shell and Tube Heat Exchanger Efficiency and its Relation to Effectiveness", Proceedings of the 2003 ASME International Mechanical Engineering Congress and Exposition, November 16-21, 2003.

[4] A. Fakheri, "Thermal Efficiency of the Cross Flow Heat Exchanger", Proceedings of the 2006 ASME International Mechanical Engineering Congress and Exposition, November 5-10, 2006.

[5] F. A. McClintock,"The Design of Heat Exchangers for Minimum Irreversibility",Presented at the ASME, Annual Meeting Paper No. 51-A-108, 1951.

[6] A. Bejan, "Concept of Irreversibility in Heat Exchanger Design: Counterflow Heat Exchangers for Gas-to-Gas Applications",ASME J. Heat Transfer, Vol.99, No. 3, pp. 374-380, 1977.

[7] S. Accves-Saborio, J. Ranasinghe and G. M. Reistad, "Extension to the Irreversibility Minimization Analysis Applied to Heat Exchangers", ASME J.HeatTransfer,Vol. 111, No. 1, pp. 29-36, 1989.

[8] R. K. Shah and T. Skiepo, "Entropy Generation Extrema and Their Relationship With Heat Exchanger Effectiveness- Number of Transfer Unit Behaviour for Complex Flow Arrangements", ASME J. Heat Transfer, Vol. 126, No. 6, pp. 994-1002, 2004.

[9] G. Maheshwari, A. I. Khandwawala and S. C. Kaushik,"A comparative performance analysis of an endoreversible heat engine with thermal reservoir of finite heat capacitance under maximum power density and maximum powerconditions", International Journal of Ambient Energy, Vol. 26, No. 3, pp. 147-154,2005.

[10] K. Chowdhury and S. Sarangi,"Performance of Cryogenic Heat Exchangers with Heat Leak from the Surroundings", Advances inCryogenic Engineering, Vol. 29, pp. 273-280, 1984.

[11] R. F. Barron, "Effect of Heat Transfer from Ambient to Cryogenic Heat Exchanger Performance", Advances in Cryogenic Engineering, Vol. 29, pp. 265-272, 1984.

[12] S. Al-Dini and S. Zubair, "Effectiveness-NTU Relations for Parallel Flow Heat Exchangers Subjected to Heat Leak from outside, Heat Transfer Engineering, Vol. 29, No. 5, pp. 475-483, 2008. 